\title{
Contrast Media in Time-Resolved MRA at 3T: A Systematic Quantitative and Qualitative Analysis of Concentration and Dose Effects on Image Parameters in Minipigs
}

\author{
Kontrastmittel in der zeitlich hochaufgelösten MRA bei 3T: eine \\ systematische quantitative und qualitative Analyse des Einflusses \\ von Konzentration und Dosis auf Bildparameter bei Minischweinen
}

Authors

Dariusch Reza Hadizadeh', Vera Catharina Keil'1, Gregor Jost² ${ }^{2}$ Hubertus Pietsch², Martin Weibrecht ${ }^{3}$, Christian Marx , Winfried Willinek ${ }^{4}$

Affiliations

1 Dept. of Radiology, University of Bonn, Germany

2 MR \& CT Contrast Media Research, Bayer AG, Berlin, Germany

3 Research Laboratories, Philips Technologie GmbH Innovative Technologies, Aachen, Germany

4 Center for Radiology, Neuroradiology, Sonography and Nuclear Medicine, Krankenhaus der Barmherzigen Brueder, Trier, Germany

Key words

contrast agents, gadobutrol, experimental animal model, magnetic resonance angiography, gadopentetate dimeglumine

received 08.01 .2018

accepted 09.05.2018

Bibliography

DOI https://doi.org/10.1055/a-0631-4707

Published online: 2018

Fortschr Röntgenstr 2018; 190: 747-757

(c) Georg Thieme Verlag KG, Stuttgart · New York

ISSN 1438-9029

Correspondence

Prof. Dr. Dariusch Reza Hadizadeh

Department of Radiology, University of Bonn,

Sigmund-Freud Str. 25, 53113 Bonn, Germany

Tel.: ++ 49/2 28/2 87/1 1045

Fax: $+49 / 228 / 287 / 19878$

dariusch.hadizadeh@ukbonn.de

\section{ZUSAMMENFASSUNG}

Ziel Quantitative und qualitative Analyse von Gadopentetat Dimeglumin (GD) im Vergleich zu Gadobutrol in Standarddosierung ( $(\mathrm{G} b$ ) oder mit halber Dosis (hGb) in der thorakoabdo- minellen zeitlich-hochaufgelösten Kontrastmittel-verstärkten Magnetresonanz Angiographie (4D-MRA) mit der dynamischen Computertomografie (dCT) als quantitativen Referenzstandard in Minischweinen.

Material und Methoden 7 anästhesierte Göttinger Minischweine erhielten thorakoabdominelle dCT- $(0,37$ s Rotationszeit) und 4D-MRA-Untersuchungen (0,3 s/dynamischer Phase; transversal) jeweils nach Gabe von sGb und hGb. 8 andere Minischweine erhielten koronare 4D-MRA-Untersuchungen (1,3 s/dynamischer Phase; sGb, hGb, GSD). Die dCT-Schwächung Opazifität wurde in absolute GadoliniumKonzentrationen konvertiert und zu maximalen 4D-MRA Signalintensitäts-(SI)-Spitzen verglichen. Die Bolusbreite wurde anhand der Breite des Bolus bei halber Kurvenhöhe (FWHM) quantifiziert. Die koronaren 4D-MRA-Untersuchungen dienten sowohl quantitativen als auch qualitativen Bildanalysen. Nach diesem Vergleich der Dosiseffekte auf die SI in der transversalen 4D-MRA wurden die koronaren 4D-MRA anhand quantitativer und qualitativer Parameter analysiert.

Ergebnisse In der dCT (bzw. transversalen 4D-MRA) zeigte sich nach Gabe von hGb im Vergleich zu sGb eine um 39,0\% (bzw. 14,5\%) niedrigere maximale arterielle Gadolinium-Konzentration (bzw. Spitzensignal) und ein um 20,6 \% (bzw. 33,8\%) kürzeres FWHM. Die Differenz zwischen dCT und 4DMRA ergab sich aus Plateaus oder Umkehrungen der Signalspitzen in der 4D-MRA bei 5/7 Tieren. Während unter Gabe von sGb quantitativ jeweils die höchsten Signalspitzen erreicht wurden, wurde die Bildqualität der Arterien mit allen drei Kontrastmittelapplikationen ähnlich gut bewertet, trotz quantitativ etwas höherer SI unter Gabe von sGb. Hingegen wurde die Bildqualität bei der Abbildung venöser Gefäße nach sGb-Gabe signifikant höher bewertet.

Schlussfolgerung Spitzen-Gadolinium-Konzentrationen und 4D-MRA SI-Spitzen sind nach sGb-Applikation am höchsten. Diese Unterschiede sind insbesondere in der venösen Phase der 4D-MRA evident und führen zu einer überlegenen Bildqualität in der Mehrphasen-4D-MRA. 


\section{Kernaussagen:}

- Gadobutrol in der Standarddosis erzeugt die höchsten vaskulären Gadolinium-Konzentrationen und 4D-MRASignalintensitätsspitzen.

- Absolute vaskuläre Gadolinium-Konzentrationen und 4D-MRA-Signalintensitätsspitzen divergieren bei $3 \mathrm{~T}$ in der arteriellen Bildphase.

- Plateaus oder Signalumkehrungen führen zu reduzierten arteriellen 4D-MRA-Signalintensitätspitzen bei $3 \mathrm{~T}$.

- Die arterielle Bildqualität wird mit den unterschiedlichen Kontrastmittelprotokollen ähnlich hoch bewertet.

- Die venöse Gefäßbeurteilbarkeit der 4D-MRA ist mit Gadobutrol in Standarddosis signifikant besser.

\section{ABSTRACT}

Purpose Quantitative and qualitative analysis of gadopentetate dimeglumine (GD) versus standard-dose $(\mathrm{s} G \mathrm{~b})$ and halfdose (hGb) gadobutrol in thoracoabdominal time-resolved contrast-enhanced magnetic resonance angiography (4DMRA) with dynamic computed tomography (dCT) as the quantitative reference in minipigs.

Materials and Methods 7 anesthetized Goettingen minipigs received thoracoabdominal $\mathrm{dCT}(0.37 \mathrm{~s}$ rotation time) and transverse 4D-MRA (0.3 s/dynamic frame;) using sGb and hGb. 8 other minipigs received coronal 4D-MRA (1.3 s/dynamic frame; sGb, hGb, SGD). dCT attenuation levels were converted into absolute gadolinium concentrations and compared to 4D-MRA peak signal intensities (SI). Bolus lengths were quantified by full width at half maximum (FWHM) measurements. After this comparison of dose effects on SI in transverse 4D-MRA, coronal 4D-MRAs were analyzed regarding both quantitative and qualitative parameters.
Results In dCT (transverse 4D-MRA) hGb showed 39.0\% (14.5\%) lower arterial peak gadolinium concentrations (peak SIs) and $20.6 \%$ (33.8\%) shorter FWHM compared to sGb. The difference was due to peak plateaus or reversals in 4D-MRA in 5/7 animals. While sGb led to the highest peak SIs, image quality ratings of arteries were rated similarly high with all contrast agent protocols despite a slightly higher SI with sGb. In contrast, venous peak SIs and image quality ratings were significantly higher when using sGb.

Conclusion Peak Gd concentrations and 4D-MRA peak SIs are highest with $\mathrm{SGB}$. These differences are most evident in the venous phase leading to superior image quality in multiphase 4D-MRA.

\section{Key Points:}

- Standard-dose gadobutrol offers high vascular gadolinium concentrations and 4D-MRA peak signals.

- Absolute vascular gadolinium concentrations and 4D-MRA peak signal intensities at $3 \mathrm{~T}$ diverge.

- Peak plateaus or reversals cause decreased arterial 4D-MRA peak signals at $3 \mathrm{~T}$.

- Arterial image quality is rated similarly high using different contrast agent protocols.

- Venous vessel visibility in 4D-MRA is significantly better using standard dose gadobutrol.

\section{Citation Format}

- Hadizadeh DR, Keil VC, Jost G et al. Contrast Media in TimeResolved MRA at 3T: A Systematic Quantitative and Qualitative Analysis of Concentration and Dose Effects on Image Parameters in Minipigs. Fortschr Röntgenstr 2018; 190: 747-757

\section{Introduction}

Since its introduction in the early 1990 s, contrast-enhanced and particularly time-resolved magnetic resonance angiography (4D-MRA) has made tremendous progress [1, 2]. Advanced techniques have been tested for a broad spectrum of indications and, as a result, have become part of routine clinical practice [3, 4]. However, optimization of 4D-MRA not only requires ideal pulse sequence parameters, but also dedicated contrast agent (CA) application protocols.

Physico-chemical properties including relaxivity, bolus application and concentration of gadolinium-based CAs were shown to have an impact on thoracoabdominal 4D-MRA that also depends on field-strength affecting both quantitative and qualitative aspects [5, 6]. Given its higher gadolinium concentration (1 molar), the gadolinium-based higher $r_{1}$-relaxivity macrocyclic CA gadobutrol has been shown to allow for a more compact bolus shape and possibly superior overall image quality compared to a standard dose of gadopentetate dimeglumine (0.5 molar) [7, 8].

Another important aspect is the required dose of CA for optimized 4D-MRA. Dose reduction has taken on an increasingly im- portant role in contrast-enhanced MR imaging in many centers $[9,10]$. However, while several studies on 4D-MRA reported high image quality at reduced doses of CAs, a systematic analysis of the effects of dose reduction on gadolinium concentration and signal intensity (SI) and image quality in 4D-MRA is missing [11 - 14].

The purpose of this study therefore was to

- first investigate the effects of half-dose (hGb) instead of standard-dose (sGb) gadobutrol application on 4D-MRA SI using $\mathrm{dCT}$ as the quantitative reference

- and then investigate these CA applications to an application of standard-dose gadopentetate dimeglumine regarding quantitative and qualitative parameters of arterial and venous image quality in thoracoabdominal 4D-MRA.

\section{Materials and Methods}

\section{Animals}

7 Goettingen minipigs (4 female, age $31.7 \pm 6.9$ months, 46.1 $\pm 4.0 \mathrm{~kg}$ body weight) were examined on a clinical dual-source CT and on a $3 \mathrm{~T}$ clinical whole-body MRI scanner (protocol A). 8 other 
Goettingen minipigs (7 female, age $32.1 \pm 6.1$ months, 33.4 $\pm 4.5 \mathrm{~kg}$ body weight) were examined on a $3 \mathrm{~T}$ clinical wholebody MRI scanner (protocol B).

The animals were handled in compliance with the German animal welfare legislation and with the approval of the state animal welfare committee. All animals were investigated under general anesthesia induced with ketamine, $30 \mathrm{mg} / \mathrm{kg}$ body weight i. $\mathrm{m}$. (Pharmacia, Karlsruhe, Germany), azaperone, $2 \mathrm{mg} / \mathrm{kg}$ body weight i. m. (Stresnil, Janssen-Cilag, Neuss, Germany) and atropine, $0.025 \mathrm{mg} / \mathrm{kg}$ body weight (Eifelfango Chem.-Pharm. Werke, Bad Neuenahr-Ahrweiler, Germany). Anesthesia was maintained by intravenous injection with propofol, $0.8 \mathrm{mg} / \mathrm{kg}$ (Ratiopharm, Ulm, Germany). Animals were placed in a prone position and the electrocardiograms and oxygen saturations were monitored. For $\mathrm{dCT}$ and 4D-MRA, end-expiratory breath-holds were used. CAs were administered intravenously into an ear vein using a 20-gauge access and a power injector (Medrad Spectris Solaris, Bayer US, Pittsburgh, PA, USA).

Weight, size, cardiac output, ECG and oxygen saturation and anesthesia-related complications were recorded and analyzed to rule out parameters that may influence CA bolus profiles.

\section{Experimental Setup}

This study was carried out to investigate the correlation between dose differences in vascular gadobutrol concentration and $\mathrm{SI}$ in 4D-MRA (protocol A) and to investigate the influence of different doses of gadobutrol compared to that of gadopentetate dimeglumine on image quality (protocol B) ( $\triangleright$ Fig. 1).

Protocol A ( Fig. 1a): seven animals received dynamic CT and transverse 4D-MRA with standard-dose $(0.1 \mathrm{mmol} / \mathrm{kg}$; sGb) and half-dose $(0.05 \mathrm{mmol} / \mathrm{kg}$; hGb) gadobutrol (Gadovist, Bayer Vital, Leverkusen, Germany). Therefore, each of these seven animals received 4 CA injections ( 2 for $\mathrm{dCT}$ and 2 for $4 \mathrm{D}$ - MRA). In this part of the study dose-related differences in vascular gadobutrol concentration vs. SI in 4DMRA were investigated.

Protocol B ( $\triangleright$ Fig. 1b): eight animals (different animals than those in protocol A) received coronal thoracoabdominal 4D-MRA with sGb and hGb $(1 \mathrm{ml} / \mathrm{s})$, and standard doses of $0.1 \mathrm{mmol} / \mathrm{kg}$ body weight gadopentetate dimeglumine (GD; Magnevist, Bayer Vital). In this protocol, each of the eight animals received 3 CA injections (all 4D-MRA). Protocol B was undertaken to compare image quality parameters of 4D-MRA using sGb to hGb and to GD.

All gadobutrol examinations were carried out at flow rates of $1 \mathrm{ml} / \mathrm{s}$, whereas gadopentetate dimeglumine injections were performed at $2 \mathrm{ml} / \mathrm{s}$ to allow for equimolar gadolinium applications (chemical properties of the two CAs differ with respect to concentrations and relaxivities (higher in plasma for both CAs): gadopentetate dimeglumine: linear, ionic, 0.5 molar, relaxivity in whole blood at $37^{\circ} \mathrm{C}$ and $1.5 \mathrm{~T}_{\text {of }} \mathrm{r}_{1}=4.25-4.3 \mathrm{~L} \mathrm{mmol}^{-1} \mathrm{~s}^{-1 ;}$; gadobutrol: macrocyclic, 1.0 molar, $r_{1}=4.61-5.3 \mathrm{~L} \mathrm{mmol}^{-1} \mathrm{~s}^{-1}$ ) $[6,15$, 16]. In each protocol CAs were administered in a randomized order. CA administrations were followed by $20-\mathrm{mL}$ saline flushes at the same flow rates.

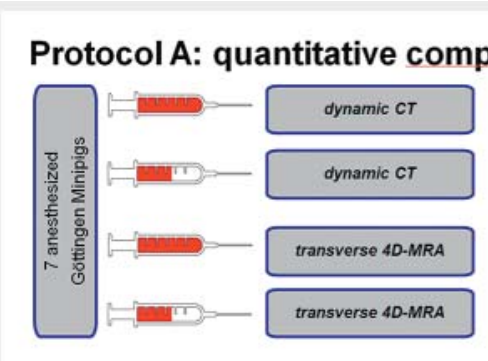

Protocol B: qualitative
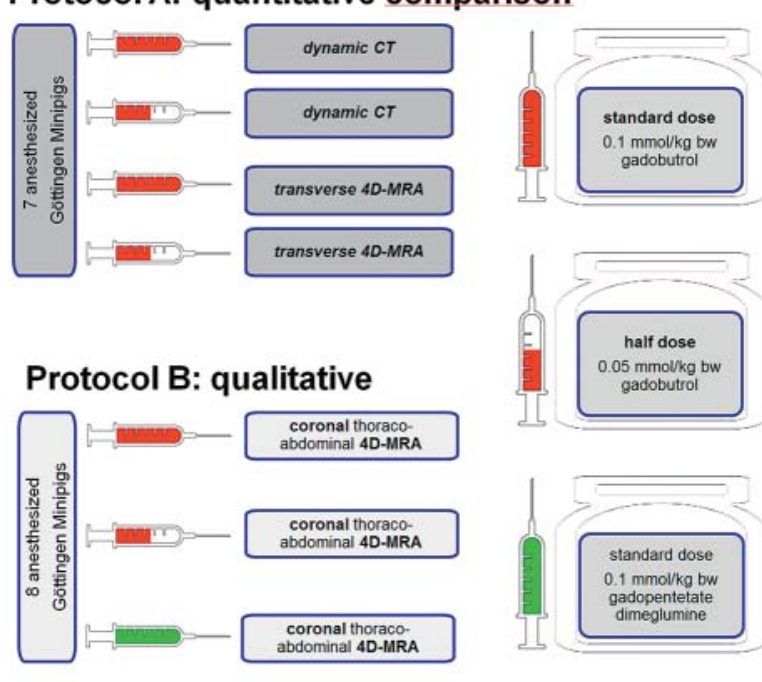

- Fig. 1 Study design including a total of 52 contrast agent applications in 15 minipigs. Protocol A: half-dose and standard-dose gadobutrol were injected into 7 minipigs for both dynamic $C T$ and transverse time-resolved contrast-enhanced MRA (4D-MRA) in separate examinations $(7 \times 4=28$ contrast agent injections). Protocol B: half-dose and standard-dose gadobutrol as well as standard-dose gadopentetate dimeglumine) were injected into 8 minipigs for the acquisition of coronal dynamic 4D-MRA examinations $(8 \times 3=24$ contrast agent injections).

- Abb. 1 Studiendesign mit insgesamt 52 Kontrastmittel-Applikationen bei 15 Minischweinen. Protokoll A: Je eine halbe und eine Standarddosis Gadobutrol wurden sieben Minischweinen sowohl für eine dynamische $\mathrm{CT}$ als auch für eine transversale zeitlich hochaufgelöste Kontrast-verstärkte MRA (4D-MRA) in getrennten Untersuchungen appliziert ( $7 \times 4=28$ Kontrastmittel-Injektionen). Protokoll B: Je eine halbe und eine Standarddosis Gadobutrol sowie eine Standarddosis Gadopentetat Dimeglumin wurden in getrennten Untersuchungen acht Minischweinen für die Akquisition von koronaren dynamischen 4D-MRA Untersuchungen appliziert $(8 \times 3=24$ Kontrastmittel-Injektionen $)$.

\section{Protocol A}

\section{Technical parameters of dynamic CT and transverse 4D- MRA}

Dynamic CT imaging was performed with a clinical dual-source 64-slice CT scanner (Definition, Siemens Healthcare, Erlangen, Germany), acquiring four transverse slices (slice thickness, $6 \mathrm{~mm}$ each) in the thoracoabdominal region covering the descending aorta, portal vein and the main hepatic arteries and veins. Technical parameters: $80 \mathrm{kV}$; $485 \mathrm{mAs}_{\mathrm{eff}}$; rotation time: $0.37 \mathrm{~s}$; reconstruction interval $=0.3 \mathrm{~s}$; no table feed; imaging time: $0-40 \mathrm{~s}$ post injection; reconstruction kernel: B30. Imaging was started simultaneously with CA injection. CT attenuations were converted into gadolinium concentrations on the basis of data from previous phantom experiments [5].

Transverse 4D-MRA of the same animals was performed in a randomized order with $45 \mathrm{~min}$. intervals to allow for elimination of the previous CA ( $\triangleright$ Fig. 2 ) in regions corresponding to those of 


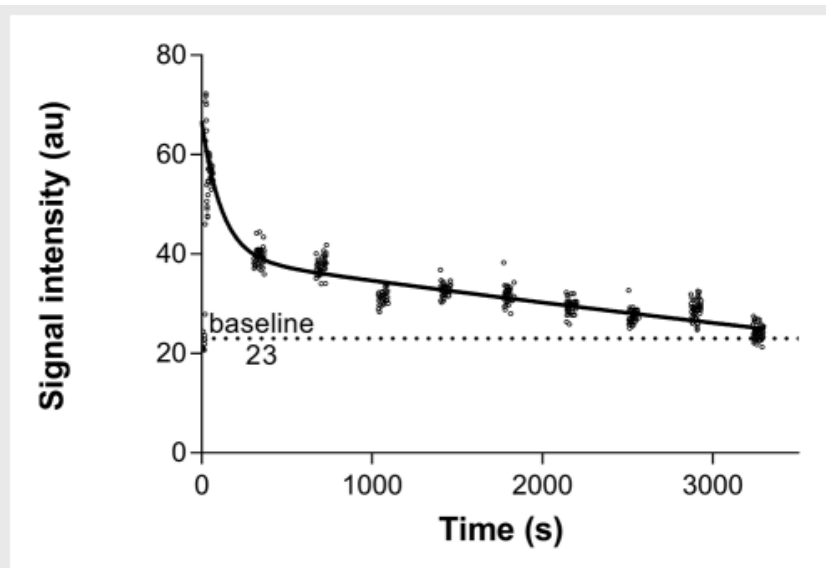

- Fig. 2 Signal enhancement in the descending aorta in one representative minipig for a period of 42.78 minutes after administration of gadobutrol determined by repeated acquisition of the transverse 4D-MRA. The individual blocks of data points represent the single measurements of the repeated 4D-MRAs. Note the recurrence of the signal intensity almost to the baseline level (23 a.u.) at the end of the repetitive scan.

- Abb.2 Signalverstärkung in der Aorta descendens am Beispiel eines Minischweins über einen Zeitraum von 42,78 Minuten nach Administration von Gadobutrol auf der Basis wiederholter Akquisitionen der transversalen 4D-MRA. Die einzelnen Blöcke von Datenpunkten repräsentieren einzelne Messungen der wiederholten 4D-MRA. Zum Endzeitpunkt der wiederholten Messungen wird die Ausgangssignalintensität nahezu erreicht (23 a. u.).

dCT experiments ( $\triangleright$ Fig. 1a). Transverse 4D-MRA slices were acquired to be able to fully cover the body region that was previously visualized and quantified by dCT with a similar temporal resolution.

4D-MRA was performed on a $3 \mathrm{~T}$ whole-body scanner (Intera, Philips Healthcare, Best/the Netherlands) using 4D-TRAK $[17,18]$. The imaging parameters of transverse 4D-MRA were as follows: TR, $7.7 \mathrm{~ms}$; TE, $1.27 \mathrm{~ms}$; FA, 25; voxel size, [1.6 $\times 1.6 \times 6.0] \mathrm{mm}^{3} ; 200$ dynamics, 16 slices each; $0.3 \mathrm{~s}$ image update time; FOV, $410 \times 410 \mathrm{~mm}^{2}$; keyhole percentage, $25 \%$; parallel imaging, SENSE, $\mathrm{P}(\mathrm{ap})=3, \mathrm{~S}(\mathrm{fh})=2$; acquisition time (AQ), $60 \mathrm{~s}$. Imaging was started $2 \mathrm{~s}$ after starting the injection of the CA.

\section{Data analysis of dynamic CT and transverse 4D-MRA}

Quantitative analysis of dCT and transverse 4D-MRA boluses included quantification of a) peak SIs (4D-MRA) / peak gadolinium concentrations (dCT), b) peak widths (FWHM) and c) time-topeak intervals (TTP) (CT, DynEva, Syngo ${ }^{\circledR}$, Siemens Healthcare; MRI, MeanCurve, Syngo ${ }^{\circledR}$, Siemens Healthcare). FWHM was defined as the time interval of the bolus from where SI reached at least $50 \%$ of the peak SI until it declined back to $50 \%$ of the peak SI. 4D-MRA peak SIs were measured at both the first and second (recirculation) arterial bolus passage.

\section{Protocol B}

\section{Technical parameters of coronal thoracoabdominal 4D-MRA}

In the second part of the study, 8 animals received coronal thoracoabdominal 4D-MRA with sGb, hGb and GD. This approach was chosen in order to obtain images similar to those in clinical human examinations in order to allow for qualitative image analysis (protocol B, > Fig. 3). As a consequence of covering large volumes with almost isotropic voxels, the temporal resolution is somewhat lower in this approach than in protocol A. Protocol B included three injections in a randomized order with $45 \mathrm{~min}$. intervals for signal renormalization ( $\vee$ Fig. 1b). Technical parameters of coronal 4D-MRA: TR, $7.7 \mathrm{~ms}$; TE, $1.27 \mathrm{~ms}$; FA, 25; voxel size, [1.5 $\times 1.5 \times 1.5] \mathrm{mm}^{3} ; 53$ slices, 40 dynamics; $1.3 \mathrm{~s}$ image update time; FOV , $410 \times 410 \mathrm{~mm}^{2}$; keyhole percentage, $25 \%$; parallel imaging, SENSE, $\mathrm{P}(\mathrm{ap})=3, \mathrm{~S}(\mathrm{fh})=2 ; \mathrm{AQ}, 52 \mathrm{~s}$. Imaging was started $2 \mathrm{~s}$ after starting $C A$ injection.

\section{Data analysis of coronal thoracoabdominal 4D-MRA}

Qualitative analyses of coronal 4D-MRA were performed in regions of interest located in twelve arterial and six venous targets (rating: 0 to 2; 0: non-visible; 1 : visible but insufficient for diagnosis; 2: diagnostic) in non-subtracted data sets at time points of visually maximum enhancement: aorta, segmental pulmonary arteries, celiac trunk, common hepatic artery, main hepatic artery, superior mesenteric artery, left and right main renal arteries and their first and second order branches, segmental pulmonary veins, superior and inferior vena cava, portal vein, first order branches of portal vein, left and right main renal veins, and superior mesenteric vein ( $>$ Fig. 3 ). Vessel visibility was judged independently by two radiologists ( 4 and 5 years of experience) blinded to the animal's identification codes, injection rates, and the administered CAs.

Overall image quality was rated in dynamic frontal-view wholevolume subtracted maximum intensity projections. The criteria for overall image quality were defined as follows: 1: poor (no diagnostic information, impossible to detect or exclude vascular abnormalities); 2: moderate (large vessels well depicted, small vessels visible but level of confidence poor for diagnostics); 3: good (diagnostic visualization of main renal and hepatic arteries at high level of confidence and smaller arteries at a moderate level of confidence); 4: excellent (visualization of intra-parenchymal arteries and large veins at a high level of confidence). The reviewers of 4D-MRA were allowed to switch back and forth between dynamic phases to select the best for vessel visualization.

\section{Statistical Analysis}

All results are given as mean \pm standard deviation. Significance was stated at $p<0.05$. After a Gaussian distribution was confirmed by the Kolmogorov-Smirnov analysis, peak enhancement, FWHM and TTP (dynamic CT, transversal 4D-MRA) and vascular SI (coronal 4D-MRA) were compared using t-tests for paired samples. Wilcoxon's matched-pairs signed-rank tests were used to compare the overall image quality ratings. Cohen's kappa was measured to compare the readers' assessments of visibility of ar- 

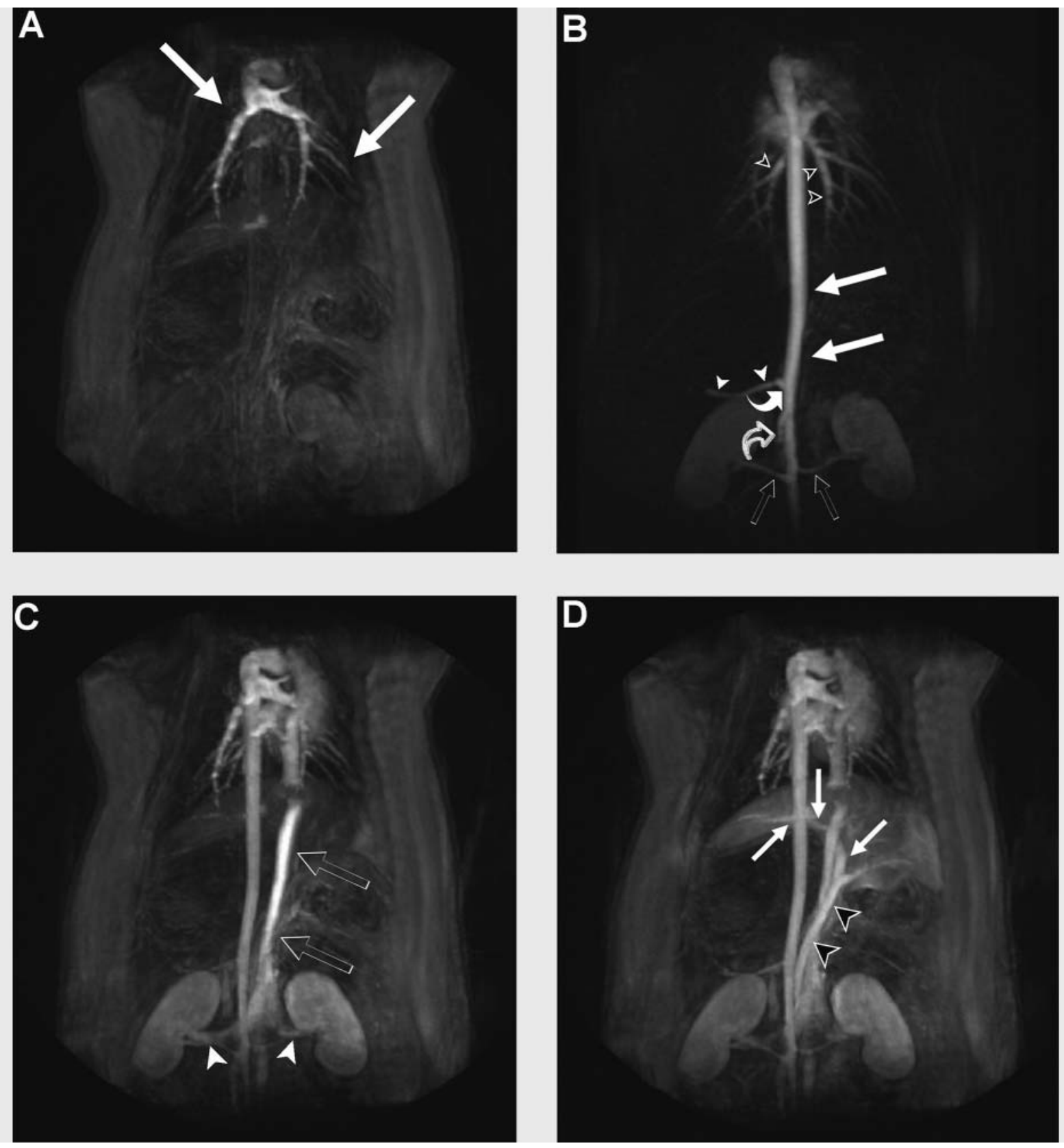

- Fig. 3 Maximum-intensity projections of thoracoabdominal time-resolved contrast-enhanced MRA (4D-MRA) in minipigs. Quantitative bolus analyses were performed in the descending aorta (straight solid arrows in B), the celiac trunk (curved solid arrow in B), the portal vein (arrowheads in D) and the inferior vena cava (hollow arrows in C) measuring the same parameters as in transverse 4D MRA. Qualitative analyses were performed at the time points of maximum enhancement in the descending aorta, celiac trunk, common hepatic and main hepatic arteries (solid arrowheads in B), superior mesenteric artery (curved hollow arrow in B), left and right main and first order branches of renal arteries (straight hollow arrows in B), segmental pulmonary arteries (arrows in A), segmental pulmonary veins (hollow arrowheads in B), superior and inferior vena cava (hollow arrows in C), main and first order branches of portal vein (arrows in D), and superior mesenteric vein (arrowheads in $\mathbf{D}$ ) as well as the main renal veins (solid arrowheads in $\mathbf{C}$ ). Note that in minipigs in contrast to humans the portal veins enhance after the hepatic veins.

- Abb. 3 Maximumintensitätsprojektionen von thorako-abdominalen zeitaufgelösten kontrastmittelverstärkten MRA (4D-MRA) bei Minischweinen. Quantitative Bolusanalysen wurden in der Aorta descendens (gerade durchgezogene Pfeile in B), dem Truncus coeliacus (gekrümmter durchgezogener Pfeil in B), der Pfortader (Pfeilspitzen in D) und der Vena cava inferior (hohle Pfeile in C) durchgeführt um dieselben Parameter zu messen wie in der transversalen 4D-MRA. Qualitative Analysen wurden zu den Zeitpunkten der maximalen KM-Anreicherung in der Aorta descendens, dem Truncus coeliacus, der Arteria hepatica und den A. hepatica- Hauptstämmen (ausgefüllte Pfeilspitzen in B), der Arteria mesenterica superior (gekrümmter hohler Pfeil in B), den linken und rechten A. renalis- Haupt- und Segmentarterien erster Ordnung (gerade hohle Pfeile in B), den pulmonalen Segmentarterien (Pfeile in A) und Segmentvenen (hohle Pfeilspitzen in B), der Vena cava superior et inferior (hohle Pfeile in C), dem Hauptstamm und Pfortaderabzweigungen (Pfeile in D) sowie in der V. mesenterica superior (Pfeilspitzen in D) sowie den linken und rechten V. renalis (Pfeilspitzen in C) durchgeführt. Zu beachten ist, dass sich die Portalvenen bei Minischweinen im Gegensatz zu Menschen erst nach den Lebervenen kontrastieren. 
terial and venous vessels in coronal 4D-MRA. Excellent agreement was stated at $\mathrm{k}>0.8$, substantial agreement at $0.6<\mathrm{k}<0.8$, moderate agreement at $0.4<\kappa<0.6$ and poor agreement at $\mathrm{k}<0.4$ [19].

The heart rate of the animals was compared by a one-way analysis of ranks followed by the Tukey test for group comparison. All statistical analyses were performed with statistical analysis software (SSIS Statistics version 22.0).

\section{Results}

All dCT and 4D-MRA examinations were successfully completed. Procedure-, anesthesia- or drug-related complications were not observed. No significant differences in heart rate were observed between the groups ( $\triangleright$ Table 1 ). The weight and size of the animals were within normal ranges and ECG and oxygen saturation were within normal rest levels during all measurements.

\section{Dynamic CT and transverse 4D-MRA}

Arterial first pass bolus peak CA concentrations and corresponding 4D-MRA SIs were compared to each other using dCT and transverse 4D-MRA and revealed marked differences between the behavior of CA concentrations and 4D-MRA SIs when reducing the CA dose to a half dose. dCT-derived peak gadolinium concentrations with sGb compared to those with hGb were significantly decreased by $38.7 \% \pm 6.0 \%(p<0.001)$, whereas 4D-MRA mean arterial peak SIs only dropped by $13.5 \% \pm 20.2 \%$ at the half dose $(p=0.327)$ ( $\triangleright$ Table 2$)$. This discrepancy of CA concentration vs. 4D-MRA SIs on the one hand and the substantial standard deviation of 4D-MRA SIs on the other hand ( $\vee$ Table 3 ) resulted from broad plateaus or peak reversals in sGb-enhanced 4D-MRA in 5/7 animals while well-defined peaks without plateaus and peak re-

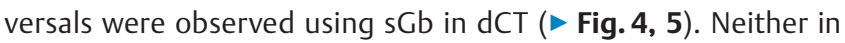
peaks of second arterial pass boluses of sGb nor in hGb boluses were broad plateaus or peak reversals of peak Sls observed. As a consequence, second arterial bolus pass peaks after sGb were almost as high as first pass peaks (sGb: $9.8 \% \pm 4.4 \%$ lower than first pass peaks, hGb: $29.9 \% \pm 8.5 \%$ lower). Other bolus characteristics of sGb compared to hGb included: $\mathrm{dCT}$, time to peak interval (TTP) reduced by $10.1 \% \pm 3.9 \%(p=0.001)$, FWHM $19.7 \% \pm 7.6$ shorter $(p<0.001)$; 4D-MRA: TTP reduced by $10.7 \% \pm 28.4 \%$ $(p=0.37)$, FWHM by $33.0 \% \pm 11.3 \%(p=0.001)$.

\section{Coronal thoracoabdominal 4D-MRA}

Qualitative analysis revealed significantly better vessel segment visibility with gadobutrol compared to that with gadopentetate dimeglumine, whereas no significant differences concerning vessel visibility were observed between sGb and hGb in arteries. Subanalysis of venous vessels ( $n=144)$, however, revealed significantly higher ratings for vessel visibility after the application of sGb $(\triangleright$ Table 3). Overall image quality was not rated significantly different with the three CA application protocols (sGb, hGb, GD; $3.14 \pm 0.59,3.07 \pm 0.40,3.10 \pm 0.52$; ranges 2 to 4 ). The interrater agreement for qualitative vessel analyses (369 readings total) by two independent and blinded readers was excellent (Cohen's k $=0.837$ ).
- Table 1 Heart rate of minipigs in experimental groups (bpm).

- Tab.1 Herzfrequenz von Minischweinen in den Versuchsgruppen (bpm).

\begin{tabular}{|c|c|c|c|}
\hline & \multicolumn{2}{|l|}{ gadobutrol } & \multirow{2}{*}{$\begin{array}{l}\text { gadopentetate } \\
\text { dimeglumine }\end{array}$} \\
\hline & standard dose & half dose & \\
\hline & $1 \mathrm{ml} / \mathrm{s}$ & $1 \mathrm{ml} / \mathrm{s}$ & $2 \mathrm{ml} / \mathrm{s}$ \\
\hline dynamic CT & $123.4 \pm 7.2$ & $124.3 \pm 11.6$ & \\
\hline $\begin{array}{l}\text { 4D-MRA } \\
\text { transverse }\end{array}$ & $120.1 \pm 8.0$ & $116.7 \pm 24.9$ & \\
\hline $\begin{array}{l}\text { 4D-MRA } \\
\text { coronal }\end{array}$ & $110.4 \pm 14.2$ & $113.4 \pm 17.6$ & $111.8 \pm 17.2$ \\
\hline
\end{tabular}

Data are provided as mean \pm standard deviation. $\mathrm{CT}$ indicates computed tomography; 4D-MRA: time-resolved contrast-enhanced magnetic resonance angiography; bpm: beats per minute.

Die Daten werden als Mittelwert \pm Standardabweichung angegeben. CT steht für Computertomographie, 4D-MRA für zeitaufgelöste kontrastmittelverstärkte Magnetresonanzangiographie und bpm für Herzschläge pro Minute.

- Table 2 Gadolinium concentrations and transverse time-resolved contrast-enhanced magnetic resonance angiography (4D-MRA) signal intensities in the descending aorta in 7 minipigs.

- Tab.2 Gadoliniumkonzentrationen und normierte Signalintensitäten der transversalen zeitaufgelöste kontrastverstärkten Magnetresonanzangiographie- (4D-MRA) in der Aorta desscendens von 7 Minischweinen.

\begin{tabular}{|c|c|c|}
\hline & \multicolumn{2}{|l|}{ gadobutrol } \\
\hline & standard dose & half dose \\
\hline & $0.1 \mathrm{mmol} / \mathrm{kg}$ & $0.05 \mathrm{mmol} / \mathrm{kg}$ \\
\hline $\begin{array}{l}\text { dynamic } \mathrm{CT} \\
\text { (attenuation in } \mathrm{HU} \text { ) }\end{array}$ & $97.0 \pm 15.8$ & $59.3 \pm 14.2$ \\
\hline $\begin{array}{l}\text { dynamic } \mathrm{CT} \\
\text { (concentration in mmol/l) }\end{array}$ & $12.2 \pm 2.0$ & $7.5 \pm 1.8$ \\
\hline $\begin{array}{l}\text { 4D-MRA transverse } \\
\text { (signal intensitiy [a. u.]) }\end{array}$ & $34.0 \pm 17.7$ & $29.4 \pm 15.8$ \\
\hline
\end{tabular}

Data are provided as mean + standard deviation. $\mathrm{CT}$ indicates computed tomography; 4D-MRA: time-resolved contrast-enhanced magnetic resonance angiography; HU: Hounsfield units; a. u.: arbitrary units. Die Daten werden als Mittelwert \pm Standardabweichung angegeben. CT steht für Computertomographie, 4D-MRA für zeitaufgelöste kontrastmittelverstärkte Magnetresonanzangiographie, HU für HounsfieldEinheiten, a. u. für willkürliche Einheiten. 
- Table 3 Vessel segment visibility in 8 minipigs using three different contrast agent protocols.

- Tab. 3 Sichtbarkeit der Gefäßsegmente in 8 Minischweinen unter Verwendung von drei verschiedenen Kontrastmittelprotokollen.

\begin{tabular}{|c|c|c|c|}
\hline & sGb vs. GD & hGb vs. GD & sGb vs. hGb \\
\hline $\begin{array}{l}\text { All vessels } \\
(n=369)\end{array}$ & $\begin{array}{l}1.46 \pm 0.75 \text { vs } \\
1.31 \pm 0.78^{1}\end{array}$ & $\begin{array}{l}1.44 \pm 0.75 \text { vs. } \\
1.31 \pm 0.78^{1}\end{array}$ & $\begin{array}{l}1.46 \pm 0.75 \text { vs } \\
1.44 \pm 0.75^{2}\end{array}$ \\
\hline $\begin{array}{l}\text { Subanalysis of } \\
\text { venous vessels } \\
(n=144)\end{array}$ & $\begin{array}{l}1.62 \pm 0.62 \text { vs } \\
1.35 \pm 0.69^{1}\end{array}$ & $\begin{array}{l}1.52 \pm 0.67 \text { vs. } \\
1.35 \pm 0.69^{1}\end{array}$ & $\begin{array}{l}1.62 \pm 0.62 \text { vs } \\
1.52 \pm 0.67^{3}\end{array}$ \\
\hline
\end{tabular}

Data are provided as mean \pm standard deviation. $\mathrm{hGb}$ : indicates gadobutrol at half dose, sGb: indicates gadobutrol at standard dose, GD: indicates Gadopentetate dimeglumine at standard dose.

Die Daten werden als Mittelwert \pm Standardabweichung angegeben. hGb steht für Gadobutrol bei Halbdosis, sGb steht für Gadobutrol bei Standarddosis, GD steht für Gadopentetat-Dimeglumin bei Standarddosis.

${ }^{1}$ indicates signficantly higher image quality rating at $p<0.001$. steht für signifikant höhere Bildqualität-Wertungen mit einem $p<0,001$.

2 indicates not signficantly different image quality ratings at $p=0.57$. steht für nicht signifikant unterschiedliche Bildqualitätsbewertungen bei $p=0,57$.

3 indicates signficantly higher image quality ratings at $p<0.05$. steht für signifikant höhere Bildqualität-Wertungen mit einem $p<0,05$.

Quantitative data analysis of high-spatial resolution coronal 4D-MRA revealed similar maximum first-passage arterial bolus peak SIs to that of high-temporal resolution transverse 4D-MRA for sGb, hGb and GD ( $\triangleright$ Table 4). In coronal 4D-MRA broad plateaus or peak reversals of first-pass arterial bolus peak SIs were found in 6/8 animals after sGb applications, in 3/8 animals after receiving the GD and in no animal after hGb. Second arterial bolus pass peaks were significantly higher when applying sGb compared to the other two CA application regimens ( $\triangleright$ Table 4 ). Venous bolus pass peaks in the inferior vena cava and portal vein were highest after sGb ( $>$ Table 4, $>$ Fig. 6): inferior vena cava: $23.5 \%$ higher than GD ( $p=0.389)$ and $35 \%$ higher than hGb $(p=0.045)$; portal vein: $7.6 \%$ higher than GD $(p=0.609)$ and $54.1 \%$ higher than hGb $(p<0.001)$.

\section{Discussion}

As increasingly efficient 4D-MRA techniques become available, the evidence for their usefulness in clinical applications is growing [4]. With this comes a growing need for evidence-based optimization of CA application protocols. This inter- and intra-individual, multimodality study shows marked differences between absolute vascular gadolinium concentrations and 4D-MRA peak SIs and benefits of standard-dose gadobutrol over half-dose gadobutrol and gadopentetate dimeglumine particularly in venous phases of 4D-MRA at 3 T using an animal model and both $\mathrm{dCT}$ and 4D-MRA to allow for intra-individual comparisons of absolute CA concentrations to 4D-MRA SIs with identical CA application parameters.
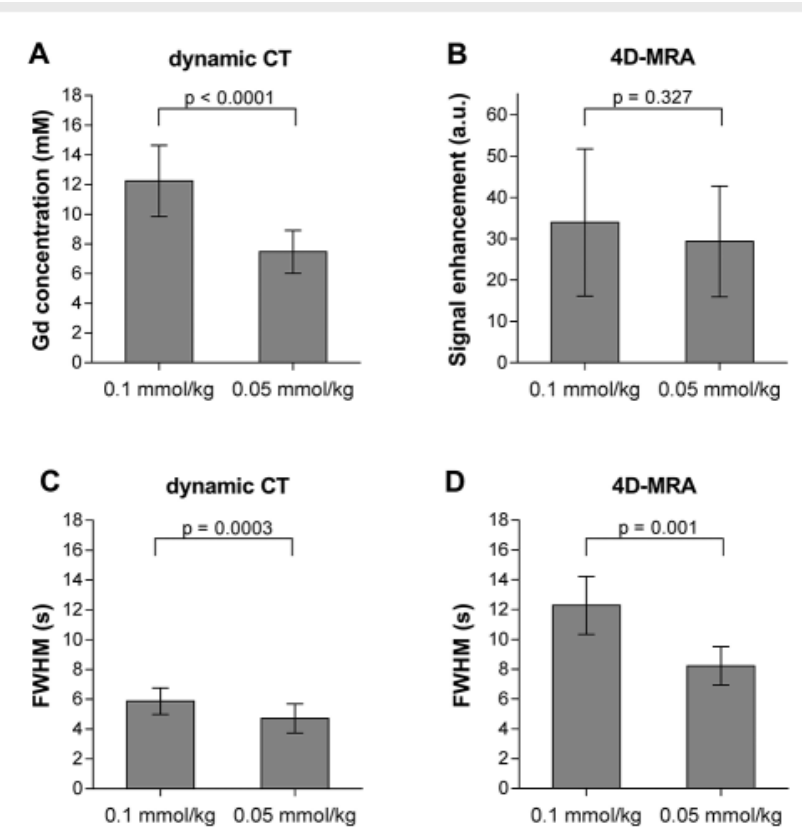

- Fig. 4 Peak properties in dCT and 4D-MRA measured in the descending aorta in seven minipigs. A, C Gadolinium peak concentrations as determined by dynamic $\mathrm{CT}$ ( $\mathrm{dCT}$; $\mathbf{A}$ ) and peak signal intensity enhancement $\mathrm{s}(\mathrm{SI})$ in transverse time-resolved contrastenhanced MRA (4D-MRA; C). B, D Bolus peak width (FWHM) in dynamic CT (dCT; B) and transverse time-resolved MRA (4D-MRA; D). Error bars represent standard deviations; P-values indicating possible significance are given within the figure.

- Abb. 4 Peak-Eigenschaften in dCT und 4D-MRA gemessen in der Aorta descendens in sieben Minischweinen. A, C Anhand dynamischer CT (dCT; A) bzw. maximaler Signalintensitätsverstärkung (SI) in transversal zeitaufgelösteten kontrastverstärkten MRA (4D-MRA; C) bestimmte Gadolinium-Spizenkonzentrationen. B, D Bolus-PeakBreite (FWHM) im dynamischen CT (dCT; B) und transversal zeitaufgelösten MRA (4D-MRA; D). Fehlerbalken repräsentieren die Standardabweichungen. Die p-Werte der Signifikanztests sind in der Abbildung angegeben.

\section{Arterial phase of 4D-MRA}

Arterial 4D-MRA peak SIs were shown to be similarly high with each of the three tested injection protocols at $3 \mathrm{~T}$ even though higher absolute vascular gadolinium peak concentrations were quantified by dCT when using sGb. Analysis of first-pass arterial bolus shapes indicates that broad plateaus or peak reversals of peak SIs in 4D-MRA at $3 \mathrm{~T}$ may be causing these discrepancies (broad plateaus or peak reversals of peak SIs were observed in both high-temporal resolution 4D-MRA [in 5/7 animals after application of sGb, none after hGb or during the second bolus pass] and in high-spatial resolution coronal 4D-MRA [in 6/8 animals after sGb, in 3/8 animals after GD and in none of the animals after hGb]). Possible reasons include confounding factors such as different CA relaxivities and pulse sequence parameters as well as too high Gd concentrations and resulting T2* effects [20].

According to the above-mentioned quantitative results, the qualitative parameter of arterial vessel visibility was rated high in 4DMRA even when using half-dose gadobutrol. Therefore, this study 


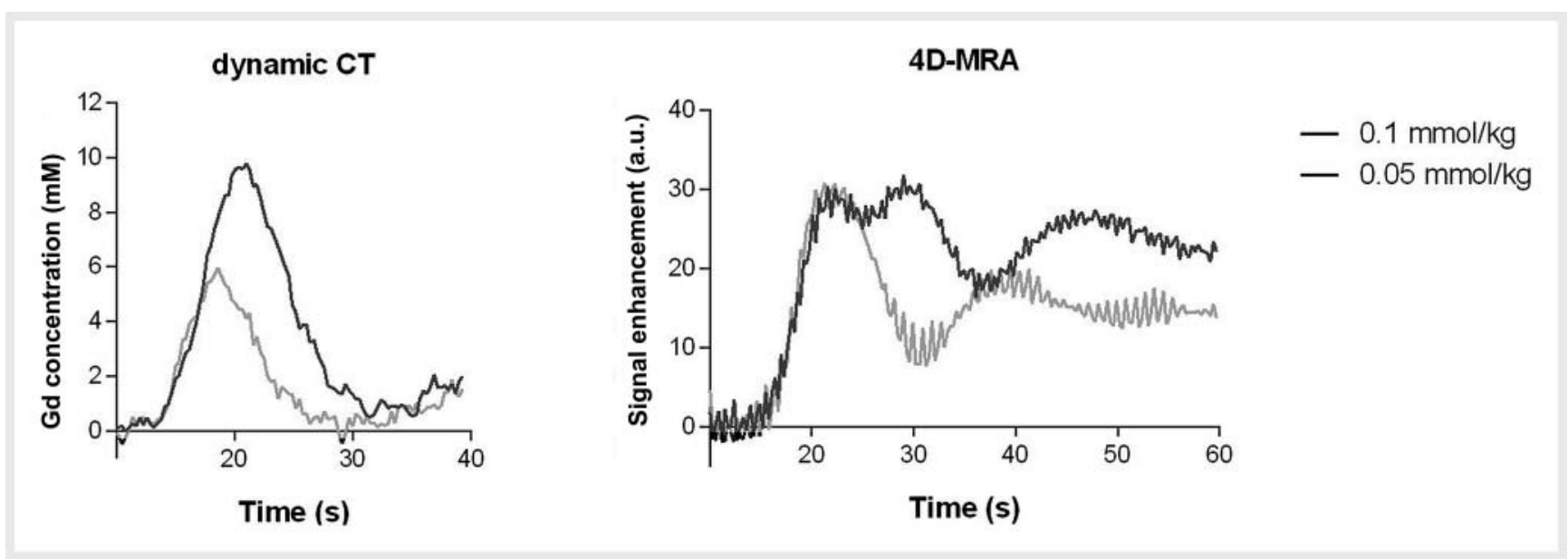

- Fig. 5 Impact of gadobutrol dose on arterial bolus profile: intra-individual comparison of bolus curves in one representative example (gray: halfdose gadobutrol, black: standard-dose gadobutrol) determined in the descending aorta at the level of the diaphragm by dynamic CT (dCT) and transverse time-resolved contrast-enhanced MRA (4D-MRA). Note the marked difference of second pass bolus peaks between imaging modalities. While in $\mathrm{dCT}$ opacification levels depend on gadolinium concentration and bolus parameters such as injection time, in 4D-MRA signal intensity enhancement behaves non-linear as it depends on magnetization effects. A broad plateau and slight peak reversal of peak SI is observed in this case when using a standard dose of gadolinium at $3 \mathrm{~T}$.

- Abb.5 Einfluss der Gadobutrol-Dosis auf das arterielle Bolusprofil: Intra-individueller Vergleich der Boluskurven in einem repräsentativen Beispiel (grau: Halbe Dosis Gadobutrol, schwarz: Standarddosis Gadobutrol) bestimmt in der Aorta descendens auf Höhe des Zwerchfells anhand dynamischer CT (dCT) bzw. transversal zeitaufgelöster kontrastverstärkter MRA (4D-MRA). Man beachte einen deutlichen Unterschied der Bolus-Spitzen während der zweiten Kontrastmittelpassage zwischen den Bildgebungsmodalitäten. Während in der dCT die Opazität von Gadolinium-Konzentration und Bolusparametern wie der Injektionszeit abhängen, verhält sich die Signalintensitätsverstärkung in der 4D-MRA nicht linear, da sie von Magnetisierungseffekten abhängt. Ein breites Plateau und eine diskrete Umkehr der Signalintensitätsspitzen wird in diesem Fall unter Verwendung einer Standarddosis von Gadolinium bei $3 \mathrm{~T}$ beobachtet.

- Table 4 Peak signal intensity enhancement in 8 minipigs in coronal time-resolved contrast-enhanced magnetic resonance angiography (4D-MRA) using half and standard doses of gadobutrol and a standard dose of Gadopetetate dimeglumine.

- Tab.4 Maximale Signalintensitätsverstärkung in 8 Minischweinen in koronarer zeitaufgelöster kontrastverstärkter Magnetresonanzangiographie (4D-MRA) unter Verwendung von Halb- und Standarddosierungen von Gadobutrol und einer Standarddosis Gadopetetat-Dimeglumin.

\begin{tabular}{|c|c|c|c|}
\hline & \multicolumn{2}{|l|}{ gadobutrol } & \multirow{2}{*}{$\begin{array}{l}\text { gadopentetate dimeglumine } \\
\text { standard dose }\end{array}$} \\
\hline & standard dose & Half dose & \\
\hline & $1 \mathrm{ml} / \mathrm{s}$ & $1 \mathrm{ml} / \mathrm{s}$ & $2 \mathrm{ml} / \mathrm{s}$ \\
\hline \multicolumn{4}{|l|}{ aorta and branches } \\
\hline first bolus passage & $49.2 \pm 5.1$ & $48.3 \pm 8.9$ & $46.7 \pm 12.1$ \\
\hline second bolus passage & $40.1 \pm 4.8^{1,2}$ & $28.7 \pm 9.4$ & $31.9 \pm 7.4$ \\
\hline inferior vena cava & $39.5 \pm 7.9^{1}$ & $29.3 \pm 6.3$ & $32.0 \pm 7.8$ \\
\hline vena portae & $32.0 \pm 6.5^{1}$ & $20.8 \pm 6.0$ & $29.7 \pm 4.6$ \\
\hline \multicolumn{4}{|c|}{$\begin{array}{l}\text { Data are provided as mean } \pm \text { standard deviation. 4D-MRA: time-resolved contrast-enhanced magnetic resonanc } \\
\text { Die Daten werden als Mittelwert } \pm \text { Standardabweichung angegeben. 4D-MRA steht für zeitaufgelöste kontrastmi } \\
1 \text { indicates signficantly higher SIs than 4D-MRA with half dose gadobutrol at } p<0.05 \text {. } \\
\text { steht für signifikant höhere SIs als in der 4D-MRA mit halber Dosis Gadobutrol }(p<0,05) \text {. } \\
2 \text { indicates signficantly higher SIs than 4D-MRA with standard dose Gadopentetate dimeglumine at } p<0.05 \text {. } \\
\text { steht für signifikant höhere SIs als in der 4D-MRA mit Standarddosis Gadopentetat Dimeglumin }(p<0,05) \text {. }\end{array}$} \\
\hline
\end{tabular}




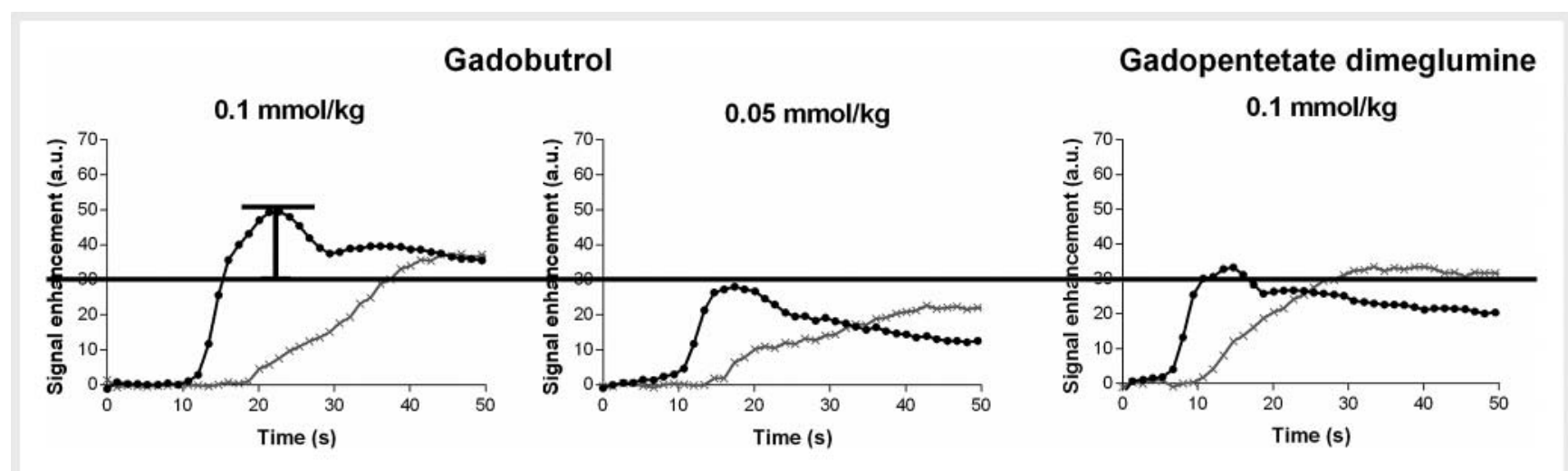

- Fig. 6 Coronal time-resolved contrast-enhanced MRA (4D-MRA) signal intensities (SI) in the vena portae (light gray) and in the vena cava inferior (black) after application of standard doses of either gadopentetate dimeglumine or gadobutrol and after application of a half dose of gadobutrol. All signals were measured within the same examination with baseline normalized SI levels. Note the markedly increased SI of the vena portae when applying the standard dose of gadobutrol.

- Abb. 6 Koronare zeitaufgelöste kontrastmittelverstärkte MRA (4D-MRA) Signalintensitäten (SI) in der Vena portae (hellgrau) und in der Vena cava inferior (schwarz) nach Applikation von Standarddosen Gadopentetat Dimeglumin und Gadobutrol bzw. einer halben Dosis Gadobutrol. Alle Signale wurden innerhalb derselben Untersuchung mit auf die den Ausgangswert normalisierten Signalwerten gemessen. Zu beachten sind im Vergleich deutlich erhöhte Signalintensitäten in der Vena portae bei Anwendung der Standarddosis Gadobutrol.

may explain earlier observations regarding high arterial image quality of 4D-MRA using lower than standard CA doses [11, 13, 14].

In line with previous studies, it shows significantly higher MRA peak SIs and significantly better vessel delineation in 4D-MRA with gadobutrol application than with gadopentetate dimeglumine $[8,21-23]$.

The current study further confirms earlier findings regarding arterial CA bolus shapes and bolus arrival times at $1.5 \mathrm{~T}$ and shows that they similarly exist at $3 \mathrm{~T}$ with gadobutrol providing more compact bolus shapes [shorter FWHM] and higher peak SIs in 4D-MRA compared to gadopentetate dimeglumine [5].

\section{Venous phase of 4D-MRA}

Recently, it has been increasingly recognized that (in contrast to high-spatial resolution static 3D-MRA) it is important to also acknowledge the venous phases of 4D-MRA in order to provide appropriate and complete data analysis of 4D-MRA [9, 10, 24, 25].

During the era of blood-pool CA (after discontinuation of gadofosveset in North America in August 2016, the only clinically approved blood-pool CA became unavailable worldwide), clinically important and unsuspected findings including incidental thromboses were described in the literature thanks to the availability of venous as well as arterial imaging [26].

In that context a possible benefit of venous imaging using sGb (significantly higher venous vessel peak SIs and better venous vessel visibility in 4D-MRA at $3 \mathrm{~T}$ compared to hGb and GD) may become particularly interesting [26, 27]. Future studies that further elucidate the potential of gadobutrol for venous imaging are therefore desirable.

\section{Limitations}

Some limitations of this study have to be acknowledged. First, an animal model may never fully reflect human anatomy and physiology. Knowledge of differences between humans and minipigs is required to allow for an appropriate image quality rating. For instance, in minipigs the sequence of vessel enhancement in 4DMRA differs from that in humans in that the inferior vena cava enhances before the portal vein does. However, minipig models have proven effective for testing of CAs in MR imaging administration in settings where human experiments were not available or appropriate [5, 28]

Second, the number of animals limits the statistical power of the obtained data. However, taking into account the ambitious intra-individual study design including both $\mathrm{CCT}$ and 4D-MRA in each animal, the number of experiments that can be realized is limited. On the other hand, the intra-individual study design necessary to be able to directly compare absolute gadolinium concentrations in $\mathrm{CCT}$ to 4D-MRA signal intensities while avoiding differences, for instance, in co-founding factors such as inter-individual cardiovascular status, may be considered a unique source for the optimization of future 4D-MRA CA application protocols [29]. Future studies on a broader variety of CAs and CA doses that analyze their impact on peak 4D-MRA SIs and image quality are desirable but beyond the scope of this study. Third, the time intervals of 45 min between examinations may be regarded as a limitation of the study. However, due to the randomized application order of CAs and the return of signal levels to almost baseline levels before 45 min ( $\triangleright$ Fig. 2), residual contrast agent may not have affected 4D-MRA signal levels in a systematic fashion and to a profound degree in this study design. Furthermore, 4D-MRA using 4D-TRAK requires a high degree of temporal interpolation [4]. This may have contributed to intra-individually broader peaks in 4D-MRA compared with those observed in $\mathrm{dCT}$. The temporal fide- 
lity of 4D-MRA is thus limited and must be interpreted with care. However, in order to avoid sequence-related limitations to the extent possible, all parameters except for the applied CA were kept constant within experiments using the same modality.

\section{Conclusion}

Gadobutrol provides higher 4D-MRA peak SIs and vessel visibility than gadopentetate dimeglumine. At $3 \mathrm{~T}$ maximum arterial peak SIs in 4D-MRA suffer from the presence of broad plateaus or peak reversals that lead to arterial peak SIs in similar ranges with standard-dose gadobutrol, half-dose gadobutrol and standarddose gadopentetate dimeglumine. In venous phases of 4D-MRA, these effects on peaks are no longer observed and standard-dose gadobutrol provides significantly higher image quality than the other contrast agent protocols.

\section{CLINICAL RELEVANCE OF THE STUDY}

- With the data of this systematically designed study on the influence of the choice of contrast agent on image quality in time-resolved thoracoabdominal MR angiography in an animal model, protocols for this examination may be optimized in the future.

- In 4D-MRA at 3 T similar image quality and visualization of arteries are observed with different concentrations and doses of contrast agents. The reason for this may be the appearance of plateaus and peak signal reversals when using a standard dose of gadobutrol.

- Standard-dose gadobutrol, however, leads to significantly higher image quality of 4D-MRA in venous imaging phases compared to half-dose gadobutrol or gadopentetate dimeglumine and should be preferred when all imaging phases of 4D-MRA are taken into account.

\section{ABBREVIATIONS AND ACRONYMS \\ 4D-MRA time-resolved contrast-enhanced magnetic reso- nance angiography \\ CA contrast agent \\ dCT dynamic computed tomography \\ hGb gadobutrol at half dose \\ GD Gadopentetate Dimeglumine at standard dose \\ sGb gadobutrol at standard dose \\ SI signal intensity}

\section{Conflict of Interest}

The authors of this manuscript declare links to the following companies: Bayer AG, Philips Technology GmbH, Innovative Technologies, Bracco AG, GE, Philips Healthcare and Sirtex Medical. This study was conducted with the support of Bayer, AG, Berlin. The company provided the animals, their caregivers, the anesthetists and the tomographers to carry out the experiments. The co-authors G.J. and H.P. are employed by this company. The co-author M.W. is an employee of Philips Technologie
GmbH Innovative Technologies, Research Laboratories, Aachen, and helped with the data analysis. The co-author W.A.W. has held lectures in the past for Bayer AG, Bracco AG, GE, Philips Healthcare and Sirtex Medical. Co-authors of the manuscript who are employees of Bayer AG, Berlin, or Philips Technologie $\mathrm{GmbH}$, Aachen, and who may have a potential financial interest in the results of this study, had no control over the final version of this manuscript.

\section{Widmung}

Diese Arbeit widmen wir unserem langjährigen Chef, dem Ordinarius der Radiologischen Universitätsklinik Bonn, Herrn Professor Dr. Hans Heinz Schild, der seit dem 1.2.1993 die Geschicke der Klinik in jeder Hinsicht verantwortungsvoll und weitsichtig geführt hat und dem alle Mitarbeiterinnen und Mitarbeiter in fachlicher, wissenschaftlicher und persönlicher Weise sehr viel zu verdanken haben. Dies gilt vor allem für uns als verantwortliche Erst- und Letztautoren. Dafür ein herzliches Dankeschön!

\section{References}

[1] Jones RA, Haraldseth O, Muller TB et al. K-space substitution: a novel dynamic imaging technique. Magn Reson Med 1993: 830-834

[2] van Vaals J], Brummer ME, Dixon WT et al. "Keyhole" method for accelerating imaging of contrast agent uptake. J Magn Reson Imaging 1993: $671-675$

[3] Griffin M, Grist TM, Francois C]. Dynamic four-dimensional MR angiography of the chest and abdomen. Magn Reson Imaging Clin N Am 2009: 77-90

[4] Hadizadeh DR, Marx C, Gieseke J et al. High temporal and high spatial resolution MR angiography (4D-MRA). Rofo 2014: 847-859

[5] Hadizadeh DR, Jost G, Pietsch $\mathrm{H}$ et al. Intraindividual quantitative and qualitative comparison of gadopentetate dimeglumine and gadobutrol in time-resolved contrast-enhanced 4-dimensional magnetic resonance angiography in minipigs. Invest Radiol 2014: 457-464

[6] Rohrer M, Bauer H, Mintorovitch J et al. Comparison of magnetic properties of MRI contrast media solutions at different magnetic field strengths. Invest Radiol 2005: 715-724

[7] Forsting M, Palkowitsch P. Prevalence of acute adverse reactions to gadobutrol-a highly concentrated macrocyclic gadolinium chelate: review of 14299 patients from observational trials. Eur J Radiol 2010: e186 - e192

[8] Goyen M, Lauenstein TC, Herborn CU et al. 0.5 M Gd chelate (Magnevist) versus 1.0 M Gd chelate (Gadovist): dose-independent effect on image quality of pelvic three-dimensional MR-angiography. J Magn Reson Imaging 2001: 602-607

[9] Eddleman CS, Jeong HJ, Hurley MC et al. 4D radial acquisition contrastenhanced MR angiography and intracranial arteriovenous malformations: quickly approaching digital subtraction angiography. Stroke 2009: $2749-2753$

[10] Krishnamurthy R, Bahouth SM, Muthupillai R. 4D Contrast-enhanced MR Angiography with the Keyhole Technique in Children: Technique and Clinical Applications. Radiographics 2016: $523-537$

[11] Attenberger UI, Haneder S, Morelli JN et al. Peripheral arterial occlusive disease: evaluation of a high spatial and temporal resolution 3-T MR protocol with a low total dose of gadolinium versus conventional angiography. Radiology 2010: 879-887

[12] Frayne R, Omary RA, Unal O et al. Determination of optimal injection parameters for intraarterial gadolinium-enhanced MR angiography. J Vasc Interv Radiol 2000: 1277-1284

[13] Hartung MP, Grist TM, Francois C]. Magnetic resonance angiography: current status and future directions. J Cardiovasc Magn Reson 2011: 19 
[14] Hwang KP, Green JD, Li D et al. Minimizing contrast agent dose during intraarterial gadolinium-enhanced MR angiography: in vitro assessment. J Magn Reson Imaging 2002: 55-61

[15] Tombach B, Heindel W. Value of 1.0- M gadolinium chelates: review of preclinical and clinical data on gadobutrol. Eur Radiol 2002: 1550 - 1556

[16] Shen Y, Goerner FL, Snyder C et al. T1 relaxivities of gadolinium-based magnetic resonance contrast agents in human whole blood at 1.5, 3 , and 7 T. Invest Radiol 2015: 330-338

[17] Hadizadeh DR, Gieseke J, Beck G et al. View-sharing in keyhole imaging: Partially compressed central k-space acquisition in time-resolved MRA at 3.0T. Eur J Radiol 2011: 400 - 406

[18] Willinek WA, Hadizadeh DR, von Falkenhausen M et al. 4D time-resolved MR angiography with keyhole (4D-TRAK): more than 60 times accelerated MRA using a combination of CENTRA, keyhole, and SENSE at 3.0T. J Magn Reson Imaging 2008: 1455-1460

[19] Landis JR, Koch GG. The measurement of observer agreement for categorical data. Biometrics 1977: 159-174

[20] Weinmann H], Laniado M, Mutzel W. Pharmacokinetics of GdDTPA/ dimeglumine after intravenous injection into healthy volunteers. Physiol Chem Phys Med NMR 1984: 167-172

[21] Fink C, Puderbach M, Ley S et al. Contrast-enhanced three-dimensional pulmonary perfusion magnetic resonance imaging: intraindividual comparison of $1.0 \mathrm{M}$ gadobutrol and $0.5 \mathrm{M}$ Gd-DTPA at three dose levels. Invest Radiol 2004: $143-148$

[22] Herborn CU, Lauenstein TC, Ruehm SG et al. Intraindividual comparison of gadopentetate dimeglumine, gadobenate dimeglumine, and gadobutrol for pelvic 3D magnetic resonance angiography. Invest Radiol 2003: 27-33
[23] Kramer JH, Arnoldi E, Francois C] et al. Dynamic and static magnetic resonance angiography of the supra-aortic vessels at 3.0 T: intraindividual comparison of gadobutrol, gadobenate dimeglumine, and gadoterate meglumine at equimolar dose. Invest Radiol 2013: 121 - 128

[24] Boos M, Scheffler K, Haselhorst R et al. Arterial first pass gadolinium-CM dynamics as a function of several intravenous saline flush and Gd volumes. J Magn Reson Imaging 2001: 568 - 576

[25] Jang J, Kim BS, Sung J et al. Subtraction MR Venography Acquired from Time-Resolved Contrast-Enhanced MR Angiography: Comparison with Phase-Contrast MR Venography and Single-Phase Contrast-Enhanced MR Venography. Korean J Radiol 2015: 1353-1363

[26] Hadizadeh DR, Kukuk GM, Fahlenkamp UL et al. Simultaneous MR arteriography and venography with blood pool contrast agent detects deep venous thrombosis in suspected arterial disease. Am J Roentgenol 2012: $1188-1195$

[27] Enden T, Storas TH, Negard A et al. Visualization of deep veins and detection of deep vein thrombosis (DVT) with balanced turbo field echo (b-TFE) and contrast-enhanced T1 fast field echo (CE-FFE) using a blood pool agent (BPA). J Magn Reson Imaging 2010: 416-424

[28] Schnorr ], Wagner S, Abramjuk C et al. Comparison of the iron oxidebased blood-pool contrast medium VSOP-C184 with gadopentetate dimeglumine for first-pass magnetic resonance angiography of the aorta and renal arteries in pigs. Invest Radiol 2004: 546-553

[29] Benner T, Reimer P, Erb G et al. Cerebral MR perfusion imaging: first clinical application of a $1 \mathrm{M}$ gadolinium chelate (Gadovist 1.0) in a doubleblinded randomized dose-finding study. J Magn Reson Imaging 2000: $371-380$ 